\title{
Study on the Teaching Reform and Practice of the Course of Environmental Management
}

\author{
Jie Gong*, QunyingYe, Qianqian Xie, Fulin Mao, Zewei Sun \\ School of Resources and Environmental Engineering, Wuhan University of Science and Technology \\ 430081, China \\ eyrejie@163.com \\ *Corresponding author
}

\begin{abstract}
In this paper, the teaching reform and practice of Environmental Management curriculum was researched preliminarily in light of the characteristics of environmental engineering. At the same time, on the premise of the absorption of the teaching content as well as the current new environmental management research results, the teaching materials were supplemented and updated accordingly. In addition, the change of teaching method, exploratory improvement were made in both interactive and bilingual teaching, and the tentative reform of the final part of the teaching process examination was made to achieve the purpose of teaching reform and teaching quality enhancement.
\end{abstract}

Keywords-Environmental management; Teaching reform; Interactive teaching; Examination reform

\section{INTRODUCTION}

Environmental management is a major course of environmental science, environmental engineering and public service management in higher education institutions, and it's one of the most important branches of the environmental science system. It is a science that studies the most general laws of environmental management, researching the management process and movement law of human environment system by integrating the theory and method of environmental science and management science, regulating the relationship between human socioeconomic activities and environmental protection by various means, providing theoretical and methodological guidance for environmental management. Through telling the contents of environmental management, students can understand the law of the coordination between human social movement and environmental change, and master the basic knowledge and theory of environmental management system and environmental management method, and then gain the ability to engage in environmental management research and management and solve the matters of environmental management.

How to maximize the role of this course to improve students' learning initiative and enhance the effect of learning applications is what this study focuses on.

\section{OPTIMIZING THE TEACHING CONTENT}

At present, the teaching materials used in environmental management curriculum are relatively single, and many use the Environmental Management (Wenhu Ye editor in 2000 sixth edition, hereinafter referred to as the Higher Education Edition Environmental Management) published by higher education publishing house. Its contents mainly contain: pandect: introduction, fundamental theory, object, content and means of environmental management; technical support and assurance part of environmental management: environmental monitoring, environmental standards, environmental audit; introduction to environmental management classification: regional environment management, enterprise environmental management, natural resource conservation and management, brief introduction of foreign environmental management, global environmental issues and management [1]. The basic theory of environmental management in this textbook is described systematically, but some examples can't keep up with the development of today's environmental management situation when time goes by, hence it cannot reflect the cuttingedge developments of environmental management. Therefore, it is necessary to adjust and enrich the contents of the environmental management courses.

The arrangement of the contents of the course depends on the specific requirements of each specialty. This curriculum is generally the professional basic course, whose class hours are 36 hours or so, namely 2 credits. Combined with our teaching practice, according to the syllabus and student-oriented principles, the contents and order of the course are adjusted and reformed as follows.

Firstly, make appropriate increase or decrease of the part of the environmental management technical support and guarantee. Environmental monitoring, as a basic course of environmental engineering, can be simplified accordingly because it has been taught before the study of environmental management; at the same time, the textbook for environmental law, as well as China's environmental policy, principles and systems are almost nothing involved, however, these contents describe China's environmental management development and environmental management system, including the old three items of the environmental management system and the new five items and changes in certain systems. And these are the 
facts of China's environmental management development, which play an extremely important role in Students' perceptual understanding of the environmental management.

Secondly, ISO14000 series of environmental management standards were issued by the International Organization for Standardization in 1996. The standard proposed a framework for environmental management, which has a wide range of practicality and is the new direction of environmental management in recent years. Many companies are competing to get ISO14000 certification. Students of our major should learn about the establishment of ISO14000 system, enterprises internal audit and external internal. Therefore, the ISO14000 series of environmental management systems should be added to the last section of the technical support and assurance part of environmental management to better consolidate and enrich the teaching content.

Thirdly, in the fifth to seventh chapters of Higher Education Edition Environmental Management: contents about regional environmental management, industrial enterprise environmental management, natural resource protection and management can be simplified accordingly. Making lists to corresponding comparative study after summarizing the knowledge points is better than just teaching according to the order of textbook, and it also helps the students to understand the knowledge points.

Fourthly, Higher Education Edition Environmental Management Chapter VIII is about the foreign environmental management profile, which introduces the United States, the European Union, Japan and other countries of the environmental management system and institution. It only involves four developed countries' environmental management and obviously should be updated and expanded accordingly.

\section{TEACHING METHODS}

Environmental management is a science that provides theoretical basis, method, basis and even technical basis for environmental management. It is a cross subject of Management and Environmental Science, which involves many basic theories of the two subjects. Because it is abstract and the students have limited knowledge, it's difficult for students to master them if using the traditional teaching methods; students can only passively accept knowledge which is difficult for them to digest and absorb and the knowledge point is also very difficult for them to get. In view of the characteristics of this course, the author realizes that the key of teaching is to arouse the students' interest in this subject, so it is necessary to study the teaching methods. That is to say, the content of each lesson should be carefully drawn and the form should be novel and changeable, so that students can feel the informative, interest and importance of the subject.

\section{A. Multimedia teaching}

Multimedia teaching is a well-received teaching method which now has been basically popularized in universities. The main advantages lie in the macrocosm of the microcosmic problem, the concretization of the abstract problem, the visualization of the dynamic problem and the diversification of the expression [2].

At present, the application of multimedia is mostly used in the design and production of multimedia courseware, which makes full use of fonts, colors and animation functions; and by inserting a variety of charts, images or video data, it strives to achieve a well-organized, emphasis-highlighted, impressive, informative effect. Like the Los Angeles photochemical smoke event in USA, the London smoke event and so on, the world's eight social pollution nuisance and six pollution accidents, are shown in high-quality multimedia teaching courseware to students. For chapters with some cases, such as environmental law, Chinese environmental management system and other chapters, the form of animation can be used in courseware, which is conducive to heuristic teaching.

By using the multimedia teaching method, the teacher can timely recommend some of the relevant sites to the students based on the contents of the chapters, especially leading foreign sites and related papers which can timely reflect cutting-edge environmental management, so that students can acquire a lot of the latest information and data in the aspect of theory and practice from the Internet by themselves and know the latest developments in the discipline, which can cultivate students' learning interest and initiative. Multimedia teaching method provides convenience for teachers in showing the wonderful pictures of relevant sites and important contents in the classroom, making the teaching in classroom colorful.

\section{B. Interactive teaching}

In the process of teaching, the teacher acts the leading role and students are the theme, both of which are extraordinarily significant. Teaching is the method and learning is the purpose, the former serves the latter. Thus the student-centered educational idea has been proposed in many schools in recent years. Teachers should create conditions and provide effective ways for students to enable them to initiatively participate in teaching, and make full use of students' initiative, mobilize students' enthusiasm and creativity [3]. Interactive teaching method refers to a teaching method which makes full use of teachers and students' subjective initiative in the process of teaching to form mutual dialogues, mutual discussions, mutual observations, mutual communications and mutual promotion between teachers and students. Its essence is the joint participation of teachers and students, so as to fully mobilize the enthusiasm and initiative of the both [4]

Student-teaching is an effective way of interactive teaching. Exchanging the role between teacher and students, the performance desire of students can be satisfied by teaching as a teacher. For example, the second chapter of the curriculum is the basic theory of environmental management; the author divides the students into three groups that each group is responsible for a section, and each section is a basic theory of environmental management. Each group members work in 
cooperation with a due division of tasks, acquiring relevant information and knowledge from scholastic education resources, making courseware with the content of each section, and then selecting a representative to introduce their courseware in 10 to 15 minutes; finally the teacher makes a summary to link the contents of the three sections. This lively and diversified teaching style is beneficial for students mobilizing positive thinking, developing their potential and personality, and showing their talents; thus it can be conducive to cultivating students' independent thinking, self-learning, comprehensive analysis ability and overall quality, and it achieves good teaching effect at the same time. The survey at the end of the term shows that, students generally welcome this form of instruction.

Discussion-based teaching is also a basic method of interactive teaching. The author combines it with the content of the teaching, problem-oriented, and regularly organizes students to carry out targeted classroom discussions, so that every student has the opportunity to speak on the platform. The teacher and students participate in the discussion equally, each airs his own views and we learn from each other. Higher Education Edition Environmental Management Chapter VIII, the foreign environmental management brief introduction, has introduced the environmental management system and institution of the United States, the European Union, Japan, Australia, India and other countries. Because the textbooks are old, it only involved early environmental management model in five countries. The author tries to let the students choose the interested country freely and retrieve the latest literature about the environmental management of the country, then combine it with the relevant knowledge points in the textbook and discuss with China's environmental management characteristics. In the process of teaching this section, we started from country's brief introduction, including geographical location and current environmental situation, students briefly introduced systems, institutions, and key characteristics of environmental management in countries like France, Germany, Finland, Sweden, Canada, Japan, the United States, India and other countries. And they made relevant comparison and discussion with China's environmental management development status and characteristics at the same time. This lesson is varied in form, and students used multimedia, a large number of charts, audio and video files to make the boring contents interesting and popularized knowledge with their own language. Although some of the statements were slightly immature, their open, divergent, creative thinking also gave the author countless inspiration. This interaction between teachers and students truly achieved the unity of teaching and learning

\section{The initial practice of bilingual teaching}

Bilingual teaching generally refers to the use of second language in the school for the teaching of the professional courses, the connotation of which varies by country, region and it mainly means to use foreign original professional teaching materials in our country. In addition to Chinese, a foreign language (currently mainly in English) is used as the main language in the classroom for public and professional teaching [5].

For the partial section content in the first chapter of the Higher Education Edition textbook, the author attempted to use bilingual teaching. For the process of class teaching, we tried to use heuristic methods, making the basic concepts and theoretical narration exact and easy to understand, and the introduction of environmental management tried to combine theory with practice as far as possible. The author deeply understood that the interpretation of 'key words' was a very important part of bilingual teaching, which was directly related to students' understanding and mastery of concepts, theories and methods. Thus, while explaining every new knowledge point, the author strove to explain the 'key words' thoroughly first, and through putting forward questions, inspiring and taking examples to make students understand the meaning accurately.

Before the start of class, the contents of the last lesson and the knowledge to be used in this lesson will be reviewed together with students, which plays pivot roles, and then the teaching of this lesson will be outlined in English. In the teaching process, students' questions are encouraged, and they will be asked to answer questions, which could make students concentrate on lectures, activate) classroom atmosphere, promote students to express themselves and increase the communication of teachers and students. In the meanwhile, it is flexible to use the ratio of English and Chinese in the lectures. For the simple content, it will be explained in English; the focal content and keywords will be narrated by Chinese after English explanation. For teachers and students who have just come into contact with bilingual teaching, the proportion of English can be reduced appropriately in the adaptive phase, and then gradually increase the proportion of English.

In the initial attempt at bilingual teaching, the author deeply waked up to the necessity of strengthening English proficiency, searching for suitable English teaching materials, supplying the lack of textbook by referring to the relevant books and impart the latest and cutting-edge knowledge to students by keeping track of the latest developments in the profession. 


\section{EXPLORATION ON THE REFORM OF EXAMINATION}

The examination is the final part of the teaching process. The contents and methods of the examination should fully reflect the purpose and requirements of the teaching. However, as a mean to examine the students' learning level and teachers' teaching level, many colleges and universities have not been out of the examination-oriented education. Examination methods are lack of diversity and comprehensiveness, and can't fully play the function of the examination and affect the enthusiasm of both teaching and learning. At present, tests of many courses are very monotonous, appear as five more than five-closed-book exam is more than open-book examination; written examination than oral, special discussion and other ways; theoretical knowledge than the ability, quality inspection summary or the final exam than the process examination; standardized examination than the comprehensive examination, it lack of dynamic information feedback in teaching process in the absence of assessment and testing in peacetime.

Concerned about the actual circumstances of the curriculum of environmental management, the author carried out the following exploration: the usual results was accounted for about $30 \%$ of the total score of the course, of which 10 points reflected the daily study of students, including attendance, classroom questions ; 10 were about the performance of classroom discussion. Another 10 points were for the expression in group teaching giving by students. For the students who performed particularly in the class would get full marks in usual results. The final results of students were the combination of the final test and the daily performance. In the process of designing test paper, the types of question were no less than four kinds, the proportion of the objective question was increased and the type of case analysis was adopted, which increased the proportion of the practical application and the comprehensive question in order to pay attention to examine the student's ability of using the knowledge to solve practical problems. The pattern of assessment process was formed, which corrected the tendency that final results was determined by only one exam, tested the effectiveness and quality of teaching by the multiple test methods, trained self-learning and innovation ability of students.

\section{CONCLUSION}

Environmental management is a comprehensive discipline intersecting environmental science and management science. It is an extension and application of Management Science in the field of environmental protection. Through the discussion of teaching content, teaching process and teaching methods, this paper aims at improving students' learning initiative, stimulating learning motivation and improving teaching quality; and the three aspects of interactive teaching and bilingual teaching are presented in this paper, in the meanwhile, some tentative suggestions are put forward for the final exam. The author hopes to pass the most advanced knowledge to students through teaching reform and practical research, so as to achieve the purpose of teaching reform.

\section{ACKNOWLEDGMENT}

This work was supported by Hubei provincial university student innovation and entrepreneurship training program [201710488029], project of Wuhan University of Science and Technology [2017ZRC182], Teaching and research project of Wuhan University of Science and Technology [2017X060],Hubei College teaching and research project [2016237].

\section{REFERENCES}

[1] Ye Wenhu. Environmental Management [M].Higher Education Press, 2000.(In Chinese)

[2] QiuJiCai. Environmental chemistry undergraduate stage teaching methods [J]. Science and Technology Consulting Herald, 2007 (1): 193 194. (In Chinese)

[3] ZuoTieyong. 21st century innovative talents training and higher education reform [Z]. China Association for Science and Technology, 2002. (In Chinese)

[4] Zhang Liyun, Yuan Shui-lin. Discussion on interactive teaching method [J] .Journal of Shanxi University of Finance and Economics (Higher Education Edition), 2002 (4): 48-49. (In Chinese)

[5] Tang Wenyan, YuanQingKe Practice and exploration in Bilingual Teaching $[\mathrm{J}]$ Journal of Guangdong University of Technology (Social Science Edition), 2006 (12): 92-94. (In Chinese)

[6] XuPeiyao, Zhu Hongtao. Reform and Practice of the Course Examination Method of Environmental Science. Journal of Management Theory and Education.(In Chinese) 